\title{
Cultivation of Cultural Awareness in English Teaching
}

\author{
Sun Wenjing \\ Zaozhuang University, Zaozhuang, Shandong \\ Email: jingnuoshui@163.com
}

\begin{abstract}
Culture cannot be separated from language, so cultural teaching should be integrated into language teaching. However, most English teachers usually incorrectly interpret cultural teaching as the imparting of pure cultural knowledge and neglect the cultivation of students' cultural consciousness. This paper firstly expounds the differences and relationship between culture and cultural awareness, and emphasizes the connotation of cultural awareness. Then the importance of cultivating cultural awareness is discussed. Aiming at the necessity of cultivating students' cultural awareness in school, this paper puts forward some ideas of cultivating cultural awareness. To cultivate students' cultural awareness, teachers should not only improve and strengthen their own quality, realize the relationship between language and culture, and master good teaching ability, but also teach cultural knowledge through a variety of activities in teaching.
\end{abstract}

Keywords-Culture; Cultural awareness; Cultivation; English teaching

\section{INTRODUCTION}

Due to the acceleration of China's reforming and opening up, China is going out to the world, and the world is paying more attention to China. International communication is becoming increasingly frequent in various areas, especially some economic activities are crossing national borders and commodity market, and the cultural communication between different nationalities and countries are being enhanced. The exchanges between China and the rest of the world are increasing, so more and more people need to have global awareness and deep understanding of foreign cultures.

In recent years, the study of cross-cultural communication have attracted the attention in foreign language circles. Under the environment of globalization, foreign language teachers should pay attention to the cultivation of foreign language learners' competence of intercultural communication. Cultural awareness also appeared firstly in the new English curriculum, the curriculum explicitly put forward that it is necessary to develop students' consciousness of cultural communication and the requirements of basic cultural communication, and emphasized that the main purpose of English teaching is to train students' ability to use English for communication.

\section{CUlture AND CULTURAL AWARENESS}

\section{A. Relationship between language and culture}

Culture and language are inseparable, it is necessary to learn the culture of the country when learning its language. But "any language is a learned behavior of complex" [1], so it is reasonable for us to believe that language is a part of culture, but we cannot say that culture is the language. However, human experience and behavior mainly reflected by the linguistic symbols. Thus, the relationship between language and culture summarized from two aspects: on the one hand, the language system itself is one of the elements of a cultural system; on the other hand, other elements of culture system must be by the language to express [2].

\section{B. Meaning of Cultural awareness}

Cultural awareness refers to the sensitivity of foreign cultures and the similarities and differences of native cultures, and the self-consciousness of language comprehension and language output based on the target language culture in the use of foreign languages.[3] Because of the inseparability of language and culture, cultural teaching should be integrated into language teaching. However, most English teachers usually misunderstand cultural teaching, solely teach students cultural knowledge and neglect the cultivation of students' cultural consciousness. In fact, cultivating students' cultural awareness is the purpose of cultural teaching, while cultural knowledge is only the basis of cultivating cultural awareness. Cultural awareness is gradually formed in the process of learning and absorbing cultural knowledge. Therefore, English teaching should not only cultivate the basic language skills, but also put the learning and training in the context of cultural teaching, and finally enable students to acquire social communicative competence. 


\section{THE IMPORTANCE OF CULTIVATING CULTURAL CONSCIOUSNESS}

\section{A. Cultivating cultural awareness helps to promote language learning}

The time for students to learn English has been advanced from junior high school to elementary school, which shows the country's emphasis on English education. Influenced by the factors of examination-oriented rules, teachers' teaching habits, and teaching materials and so on, many teachers only pay attention to teach students vocabulary, phrases, grammar and sentence structure and cultural knowledge involves too little. In the long run, students' English quality and cultural level will be limited. When reading materials, due to the lack of corresponding cultural knowledge, students will produce misunderstanding to some words, even difficult to understand the meaning, in this way, the students not only reduces the speed of reading but also gradually lose interest to read English materials and then lose interest in learning English. The goal of the English course in education is to develop students' ability to use the language comprehensively. The formation of this ability is based on the overall development of language skills, language knowledge, emotional attitude, learning strategies and cultural awareness. Language knowledge and language skills are the foundation of comprehensive language application ability, and cultural awareness is the guarantee of proper use of language. Only when we understand the customs of English-speaking countries, the way of life, moral standards and other aspects, we can understand the cultural background of English application, so that students can learn more appropriately.

\section{B. Cultivating cultural awareness is beneficial to cultivate students' world consciousness}

Today, all countries in the world are in close contact with each other and cultural exchanges are increasingly frequent. In the influx of foreign cultures, it is inevitable that teenagers as middle school students are confused about how to view these foreign cultures and our own culture. Middle school students are on the stage of forming their own outlook on life, they felt all sorts of culture shock but difficult to judge sensibly. Once they form the wrong culture consciousness, it is difficult to change, so as a middle school teacher, it is particularly important to cultivate their cultural awareness in this period. In the teaching, we should make students understand that every culture has its own characteristics and cultural differences, to understand the world by learning English culture, and to train their consciousness of the world.

\section{Cultivating cultural awareness can help improve students' comprehensive ability}

Teachers teach cultural knowledge to students through its language, who can get its knowledge about the country's humanities, geography, history, politics, economy, education, culture, social system, life style, local conditions and customs, so as to "optimize" the students" knowledge structure. Through the cultivation of students' cultural awareness, it can improve students' application ability, and solve many problems effectively, for example: how to say, how to say more appropriate. Students learning languages especially improve culture in the process of the cultivation of communicative ability must absorb the western culture conducive to cultivate creative thinking, independent consciousness, innovation and the clear goal, the highlight of the superior quality factors such as personality, excavate the potential of learners' language learning. It is to absorb the advantages of Chinese and western culture, it can help students develop their thinking, expand their knowledge and improve their comprehensive learning quality.

\section{THE METHODS TO CULTIVATE INTERCULTURAL CONSCIOUSNESS IN FOREIGN LANGUAGE TEACHING}

Language is like laying a solid foundation for culture's generation and development and it is also an important tool in culture's communication and circulation. One of the aims of foreign language teaching is to learn the culture of the target language country, and learn to express ideas properly according to the cultural customs of the target language countries. Cultural teaching must be strengthened in foreign language teaching, and attention should be paid to cultivating students' cultural awareness and sensitivity of target language culture from the beginning. In order to cultivate students' sensitivity to the target language culture and cultural awareness, the author thinks that English teaching should start from the teaching material, classroom and daily contacts, and always pay attention to discover and taught about the cultural background of English countries, political attitudes, values, customs, religious beliefs and cultural knowledge, etc.

\section{A. Infiltrating the cultural consciousness in the textbook}

The textbook is an important resource for students to learn English. The rich content of textbooks can directly reflect the cultural connotation of language. At the same time, it is one of the main ways to infiltrate cultural knowledge. Cultural import is inseparable from the comparative analysis of Chinese and foreign cultures. Language is the carrier of culture. In textbooks, from pronunciation, vocabulary to expression, it permeates the color of foreign cultures. We can begin with the words, phrases and sentences in the textbook to fully understand and explore their cultural differences. For example, in Chinese culture, "dragon" is a noble, sacred and the embodiment of great life. Chinese people will call themselves "descendants of dragon", but in western culture, dragon is a symbol of evil. Only by recognizing their cultural differences can we avoid the communication barriers caused by different social customs and cultural backgrounds. 


\section{B. Spreading cultural background knowledge in classroom teaching}

The so-called cultural background refers to the cultural traces reflected in the language or foreign national cultural factors that can be observed from foreign languages. Foreign language learning needs a certain context, which is always closely related to the national or country of the language and its history, culture and social background. This requires that we should strengthen the teaching of cultural background when we are explaining the language knowledge and training the language ability. And classroom teaching is the main way to impart cultural background knowledge. When some one listen to some English materials, we often encounter such a problem: for some familiar materials, even if we didn't understand one or two sentences, you can guess the meaning, while for some materials, you already make every word understand, but you just don't know what to speak. The main reason is that there is very little knowledge of British and American culture background, so it is necessary for us to supplement some relevant background knowledge in listening training. In speaking English, all of us know that we should pay attention to the pronunciation, intonation. But sometimes even we use correct grammar and word collocation, we also make certain pragmatic errors due to the lack of social cultural background knowledge. Speaking can not be separated from the scene and environment. Teachers should try their best to create various language environments to expose students to it, so that they can practice in the field and understand cultural differences. In this way, we consciously combine the language form with the social environment and guide students to put themselves in English communication. In reading and writing, the difficulties in them can not be completely rely on the language knowledge itself to solve, because the work of a nation are always inseparable with the nation's cultural traditions, especially English works tend to reflect the history of western culture in the background of allusions. To this end, we can carry out cultural import in two ways: one is to introduce the culture through the cultural background knowledge about the content of the text. Another method is to summarize a cultural framework that covers the content of the text according to the contents of the text, and list corresponding items.

\section{Cultivating cultural awareness and improve communication skills in daily communication}

It is certainly not enough to infiltrate students' cultural consciousness in class, because the cultural connotation of a nation has many aspects. In everyday teaching, we can make full use of the students have mastered the native language culture knowledge and the corresponding cultural knowledge of English-speaking countries to compare and appraise, by comparison, find out the similarities and differences, and understanding, gradually develop an attitude of respect and tolerance towards foreign cultures. For example, people in English-speaking countries have longer and more frequent eye contact than Chinese people, who believe that lack of eye contact is a lack of sincerity and dishonesty. The Chinese, however, avoid looking directly at each other in order to be polite, respectful or obedient. Knowing the difference, we are not surprised by the sight of the other person when we are socialized. As long as we start from the intravenous drip in the daily teaching, precept, we will be able to help students overcome gradually in learning and using English culture may produce sense of surprise, and gradually form the identity of English culture.

\section{Improving English teachers' knowledge system, professional skills and professional beliefs.}

As English teachers themselves should have very strong English cultural awareness, this needs the teacher through various methods to enrich their cultural knowledge of English, not just to be familiar with the textbooks to improve their own culture. Only in this way can we have enough ability to cultivate students' cultural awareness. Teachers should fully realize that what they teach in each lesson contains the content of cultural consciousness, and each lesson should be carefully prepared. The improvement of teachers' professional knowledge system lies in the improvement of English cultural knowledge. On the one hand, schools should pay attention to the training of teachers' English cultural awareness, and regularly organize teachers to conduct short-term overseas visits to provide teachers with opportunities and platforms for cultural exchanges. On the other hand, relevant scholars can use the vacation time to hold some training courses for English teachers. For teachers themselves, if they want to effectively cultivate students' awareness of English culture, they need to accumulate more and develop more. To do more accumulation of at ordinary times, use the Internet, TV, books and other media, consciously cultivate their own cultural sensitivity, and, based on research, along with colleagues to complete their own knowledge skill system effective improvement. Teachers can use Internet, books and other resources to cultivate the students' cultural awareness of related knowledge, understand the culture teaching method, cultural narrator method, product analysis method, comparative method, a set of effective exhibition class and cultural awareness training activities. Teachers should improve their professional beliefs and realize the cultural knowledge can improve their self-cultivation, and cultivate the students' ability to cross-cultural communication, which is useful to the students' English learning, and can motivate oneself effectively in the classroom to carry out the cultural awareness goals. At the same time, teachers should also clarify their sense of mission and tasks. 


\section{TEACHING STRATEGIES OF CULTURAL AWARENESS}

In the specific cultural teaching process, the author thinks that the following teaching strategies can be used to effectively cultivate cultural awareness.

\section{A. Direct interpretation}

Considering that the actual meaning of some words in the English language is not equivalent to the literal meaning, some language points that may cause students difficult to understand can explained directly. Such as the cultural connotation of vocabulary, discourse the cultural background. For example, the public school (in Britain, it is a boarding private school; In the United States for public schools), a local train (slow train). Of course, teachers should also give direct interpretation to sentences that may cause ambiguity.

\section{B. Systematic introduction}

Some books, for example, the British and American culture, written by Yong-tao Zhu, can be introduced to students. It tells students British and American national characteristics, geographical environment, historical development, the government system, economy, literature, religion, customs, education, family life, welfare system, news media, festivals, race relations and social problems. The book let students to systematically understand the British culture and American culture, is the concrete application of teaching strategies.

\section{Practical experience method}

This teaching strategy emphasizes the importance of students' participation in practical activities and has a good teaching effect on the improvement of students' communicative ability. Listening and moving: in the cultural teaching, the teacher timely designs the communication culture information as a set of instructions or a task, and the students complete various actions in the virtual communication situation. About the restaurant for dinner, for example, the social scene of communication content, teachers can show first introduce a restaurant menu, and introduced the western dining etiquette and food information, students are required to show "sit down, order food, eat, invoicing, leave" such as a set of verbal and nonverbal. Carefully observe the students' performance and give the necessary comments and explanations. The practice shows that this kind of teaching activities can help students to acquire non-verbal communication behaviors in cultural communication. Culture collection: teachers' teaching combined with simulation means of physical, visual AIDS, such as multimedia courseware to present some questions about culture, dialogue or short message, and then organize students to discuss our possible verbal or nonverbal behavior. Present cultural information, for example, is about the custom of gift-giving, students read an article to introduce the story of Chinese students studying in UK gifts, then the teachers and students reprehensibility is introduced and discussed, the discussion can be compared with native corresponding cultural content. Through these introduction, discussion, comparison and analysis activities, teachers and students can improve their sensitivity to English culture.

\section{CONCLUSION}

In this paper, from the experience of the author, who is teaching English for a long time as the first line English teacher, English culture teaching can not only cultivate students' cultural awareness and enhance their communication ability, also helps stimulate their interest in learning English, develop their humanistic accomplishment, and improve their comprehensive ability of using language. Therefore, English teaching should not only include the teaching of English language skills, but also the cultivation of cultural awareness and the improvement of cultural communication ability. For the realization of English teaching is to improve students' language ability and teach them the dual goal of cultural communication, English teachers should unify the language teaching and culture teaching, really to lead them to pay equal attention to language learning and culture.

\section{REFERENCES}

[1] Geginald, S. "Culture in Language Learning," [M] New Brunswick N.J.: Rutgers, 1960.

[2] Jicheng Lin, "Language and Culture," shanghai: Shanghai Foreign Language Education Press, 2002

[3] Kramsch, C. "Context and Culture in Language Teaching," [M]. Oxford: Oxford University Press, 1993. 